\section{Loss of PTEN facilitates HIF-1-mediated gene expression}

\author{
Wayne Zundel, ${ }^{1}$ Cornelia Schindler, ${ }^{1}$ \\ Daphne Haas-Kogan, ${ }^{2}$ Albert Koong, ${ }^{1}$ \\ Fiona Kaper, ${ }^{1}$ Eunice Chen, ${ }^{1}$ \\ Alexander R. Gottschalk, ${ }^{2}$ Heather E. Ryan, ${ }^{3}$ \\ Randall S. Johnson, ${ }^{3}$ Anne B. Jefferson, ${ }^{4}$ \\ David Stokoe, ${ }^{2}$ and Amato J. Giaccia ${ }^{1,5}$

\begin{abstract}
${ }^{1}$ Mayer Cancer Biology Research Laboratory, Department of Radiation Oncology, Stanford University, Stanford, California 94305-5468 USA; ${ }^{2}$ Department of Radiation Oncology, University of California, San Francisco, California 94115 USA; ${ }^{3}$ Department of Biology, University of California, San Diego, La Jolla, California 92093-0366 USA; ${ }^{4}$ Chiron Corporation, Emeryville, California 94608 USA
\end{abstract}

In glioblastoma-derived cell lines, PTEN does not significantly alter apoptotic sensitivity or cause complete inhibition of DNA synthesis. However, in these cell lines PTEN regulates hypoxia- and IGF-1-induced angiogenic gene expression by regulating Akt activation of HIF-1 activity. Restoration of wild-type PTEN to glioblastoma cell lines lacking functional PTEN ablates hypoxia and IGF-1 induction of HIF-1-regulated genes. In addition, Akt activation leads to HIF-1 $\alpha$ stabilization, whereas PTEN attenuates hypoxia-mediated HIF-1 $\alpha$ stabilization. We propose that loss of PTEN during malignant progression contributes to tumor expansion through the deregulation of Akt activity and HIF-1-regulated gene expression.

Received August 18, 1999; revised version accepted January $14,2000$.

The PTEN tumor suppressor gene was originally isolated from a homozygous deletion on human chromosome 10q23 in glioblastoma multiformes (GBMs) (Li et al. 1997; Steck et al. 1997). Germ-line mutations in PTEN result in autosomal dominant syndromes (Cowden disease, Bannayan-Zonana syndrome) associated with an elevated risk for cancer (Liaw et al. 1997; Marsh et al. 1997). PTEN encodes a dual-specificity phosphatase, and both somatic and germ-line mutations cluster within conserved regions of the phosphatase domain (Li et al. 1997; Liaw et al. 1997; Marsh et al. 1997; Steck et al. 1997). Surprisingly, physiological targets of PTEN were found to be lipid products of the $\mathrm{PI}(3) \mathrm{K}$ proto-oncogene, PIP2 $(3,4)$ and PIP3 $(3,4,5)$ (Maehama and Dixon 1998). Taken together, PTEN negatively regulates downstream

[Key Words: PTEN; angiogenesis; glioblastoma; gene expression] ${ }^{5}$ Corresponding author.

E-MAIL giaccia@leland.stanford.edu; FAX (650) 723-7382. effectors of $\mathrm{PI}(3) \mathrm{K}$, an enzyme reported to affect multiple aspects of tumorigenesis (Fruman et al. 1998).

The proto-oncogene Akt is a Ser/Thr kinase that is a critical effector of $\mathrm{PI}(3) \mathrm{K}$ and exhibits transforming capacity (Aoki et al. 1998). Akt activity is essential for transducing growth factor and integrin-mediated antiapoptotic effects (Datta et al. 1997; Khwaja et al. 1997). Several direct phosphorylation targets of Akt have been identified: Bad, GSK-3 $\beta$, and Forkhead transcription factors (Datta et al. 1997; Pap and Cooper 1998; Brunet et al. 1999; Kops et al. 1999|. In some cell types, Akt has been reported to modulate $G_{1}$ progression via inactivation of GSK-3ß (Diehl et al. 1998). Additionally, Akt has been reported to mediate vascular endothelial growth factor (VEGF) induction under hypoxia (Mazure et al. 1997). Thus, Akt has multiple roles in tumorigenesis through the deregulation of cell cycle, enhancement of apoptotic resistance, and alteration of angiogenic potential.

Glioblastoma has one of the highest incidences of PTEN mutation $(25 \%-60 \%)$ and PTEN mutation has been strongly associated with tumor differentiation (for review, see Cantley and Neel 1999). Importantly, lowgrade gliomas rarely possess PTEN mutations, but, loss of heterozygosity (LOH) at $10 \mathrm{q} 23$ is found in $~ 70 \%$ of advanced glioblastoma (Cantley and Neel 1999). Occurrence of PTEN mutations late in tumorigenesis suggests that PTEN loss of function may provide a selective advantage for tumor expansion.

Previous studies have characterized the regulation of apoptotic sensitivity in genetically matched PTEN wildtype and null fibroblasts (Di Cristofano et al. 1998; Stambolic et al. 1998). As predicted, PTEN loss allows hyperactivation of the $\mathrm{PI}(3) \mathrm{K} /$ Akt survival pathway and leads to increased apoptotic resistance (Davies et al. 1998; Haas-Kogan et al. 1998; Li et al. 1998; Stambolic et al. 1998). Glioblastomas are one of the most difficult tumors to treat as they are resistant to chemotherapy (Petersdorf et al. 1994) and are refractory to killing by many apoptotic stimuli (W. Zundel, unpubl.). Thus, apoptotic potential is one clear phenotypic manifestation thought to be conferred to cells on loss of PTEN function.

All tumors require angiogenesis for tumor expansion (Wesseling et al. 1997). Glioblastoma, in particular, is one of the most vascularized tumors and exhibits increased expression of many proangiogenic genes such as VEGF and fibroblast growth factor (FGF) (Wesseling et al. 1997). Because PI(3)K and Akt previously have been implicated in the induction of VEGF expression by hypoxia (Mazure et al. 1997), we hypothesized that wild-type PTEN expression in PTEN mutant glioblastoma cell lines could alter the cellular response to hypoxia and subsequent VEGF expression.

\section{Results}

PTEN expression attenuates hypoxia-mediated activation of Akt

Hypoxia and growth factors (e.g., IGF-1, insulin, PDGF) 


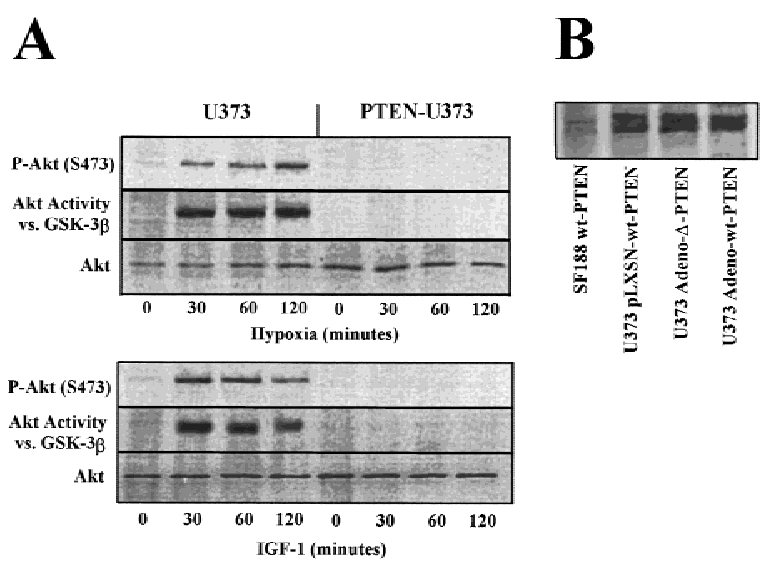

Figure 1. Hypoxia induces Akt activity that is regulated by PTEN. (A) U373 cells were retrovirally infected with wild-type PTEN and subjected to hypoxia or IGF-1 $(50 \mathrm{ng} / \mathrm{ml})$ for the indicated times. Cells were harvested and the lysates allocated for immunoblotting using $\alpha$-Phospho-Akt (S473) (top) $\alpha$-Akt antibodies or Akt kinase activity using GST-GSK-3 $\beta$ as a substrate. (B) U373 cells were either retrovirally (wt-PTEN) or adenovirally (wt or phosphatase inactive- $\triangle P T E N$ ) infected. The U373infected cells or a glioblastoma cell line possessing two wtPTEN alleles (SF188) as control were immunoprecipitated and immunoblotted with Santa Cruz SC-571 and UBI-ID 07016, respectively.

are critical modulators of tumor angiogenesis (Warren et al. 1996; Mazure et al. 1997; Zelzer et al. 1998; Wang et al. 1999). If these stimuli activate proangiogenic gene expression through a $\mathrm{PI}(3) \mathrm{K} /$ Akt-dependent pathway (Fruman et al. 1998), PTEN should block gene expression by inhibiting Akt activation in response to hypoxia. To test this hypothesis, the PTEN mutant glioblastoma cell line U373 was used to assess the effects of wild-type PTEN expression on hypoxia- and IGF-1-stimulated Akt phosphorylation and kinase activity (Fig. 1A). Hypoxia and IGF-1 stimulated Akt phosphorylation on Ser-473 and Akt kinase activity toward a GST-GSK-3 $\beta$ substrate within $30 \mathrm{~min}$, and that activity remained sustained for $>2 \mathrm{hr}$. Expression of wild-type PTEN in the same cells completely blocked hypoxia- and IGF-1-induced Akt phosphorylation and kinase activity, consistent with the inhibition of Akt by wild-type PTEN in serum-stimulated glioblastomas (Haas-Kogan et al. 1998).

We next assayed PTEN levels $72 \mathrm{hr}$ postinfection (Fig. 1B). Viral-mediated gene transfer into U373 yielded $\sim 11 \%-22 \%$-increase in PTEN levels. Retroviral infection yielded $\sim 85 \%-94 \%$ infectivity whereas the adenoviral-mediated GFP-PTEN infection efficiency was $52 \%-90 \%$.

PTEN overexpression does not alter serum deprivation or hypoxia-mediated apoptosis and only partially alters DNA synthesis

To evaluate the role of PTEN expression on DNA synthesis we analyzed $\left[{ }^{3} \mathrm{H}\right]$-thymidine incorporation in serum-deprived or mitogen-stimulated U373 cells (Fig.
2A). Wild-type PTEN, but not phosphatase-inactive PTEN, reduced DNA synthesis by $\sim 60 \%$. Although significant, DNA synthesis was not completely attenuated and the PTEN-infected cells did survive and replicate. Although these cells were under selection for PTEN expression, it is possible that the DNA synthesis observed is mediated by $10 \%-40 \%$ of uninfected cells. Hypoxia completely inhibited DNA synthesis in U373 and PTENexpressing U373, whether in the presence or absence of serum, indicating that hypoxia-mediated cell cycle arrest is dominant even in cells possessing deregulated and active Akt.

Because the role of $\mathrm{PI}(3) \mathrm{K}$ and Akt in anti-apoptotic functions is based on developmental models and transformed or immortalized cell lines, we evaluated the sensitivity of U373 to the proapoptotic stimuli of serum deprivation and hypoxia (Fig. 2B). We found that U373 and other glioblastoma cell lines are extremely resistant to many apoptotic stimuli (data not shown). However, expression of PTEN even at highly elevated levels (Fig. 1B) fails to alter apoptotic sensitivity of U373 cells to serum deprivation or hypoxia at $72 \mathrm{hr}$, despite having no detectable Akt activity (Fig. 1A). Other apoptotic stimuli,

\section{A}

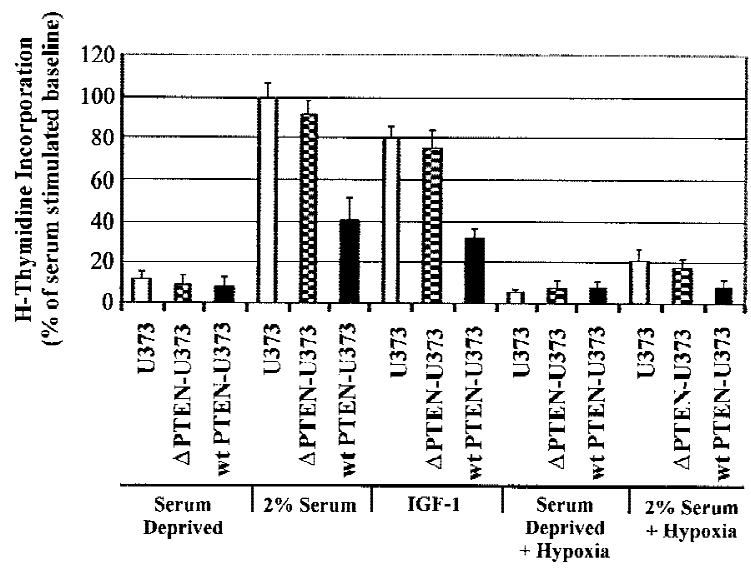

$\mathbf{B}$

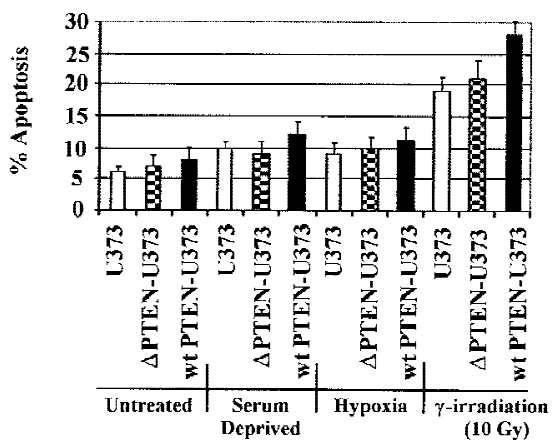

Figure 2. PTEN overexpression incompletely inhibits DNA synthesis and has minimal effects on apoptosis. U373 cells were infected with adenovirus containing wild-type or phosphatase inactive- $\triangle$ PTEN. (A) Forty-eight hours postinfection, serumstarved U373-infected cells were labeled with $\left[{ }^{3} \mathrm{H}\right]$-thymidine, treated as indicated for $24 \mathrm{hr}$, and assayed for $\left[{ }^{3} \mathrm{H}\right]$-thymidine incorporation. $(B)$ Forty-eight hours postinfection, U373-infected cells were treated as indicated and assayed for apoptosis. 


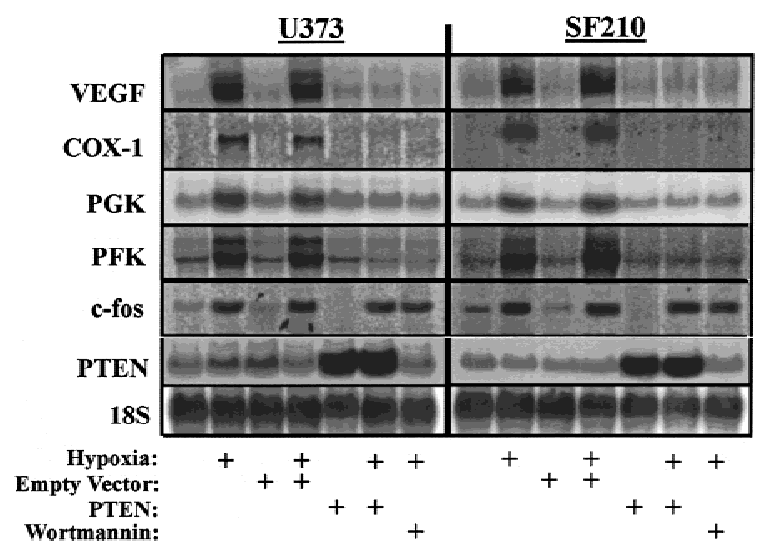

Figure 3. PTEN regulates the expression of HIF-1-regulated genes under hypoxia. U373 or SF210 cells were retrovirally infected with wild-type PTEN or empty vector control. Thirty-six hours postinfection, U373 and SF210 cells expressing PTEN or empty vector control and parental cells $\pm 100 \mathrm{nM}$ wortmannin were subjected to $9 \mathrm{hr}$ of hypoxia. mRNA was isolated and analyzed by Northern blot using VEGF, COX-1, PGK-1, PFK, c-fos, and PTEN probes.

such as $\gamma$-irradiation, only minimally sensitized glioblastoma cells to apoptosis by PTEN expression. These results suggest that glioblastomas have acquired anti-apoptotic mutations other than loss of PTEN that are sufficient to protect the cell from some physiological insults. Figure $2 \mathrm{~A}$ and $\mathrm{B}$, indicates that loss of PTEN function facilitates tumor expansion in a manner independent from its anti-apoptotic and -proliferative activities.

\section{PTEN restoration regulates expression of endogenous} hypoxia-inducible genes

To investigate whether PTEN regulates endogenous expression of hypoxia-induced genes implicated in angiogenesis, we analyzed VEGF and COX-1 mRNA expression in hypoxia-treated U373 and SF210 (Fig. 3). The expression levels of other hypoxia-inducible genes required for glycolysis $(P G K-1, P F K)$ were also analyzed. Wildtype PTEN expression and the $\mathrm{PI}(3) \mathrm{K}$ inhibitor wortmannin both blocked endogenous VEGF, COX-1, PGK-1, and $P F K$ induction in response to hypoxia when compared with empty vector controls. This effect of PTEN is not due to global down-regulation of transcription as seen by the ribosomal 18S panel. Furthermore, the negative regulation of PTEN on hypoxia-inducible genes is specific to the PI(3)K/PTEN/Akt/HIF pathway because hypoxia-induced c-fos mRNA levels (which are regulated by the MAPK pathway) are insensitive to PTEN expression. These results clearly establish a role for PTEN in the regulation of not just angiogenic factor expression but hypoxia-inducible genes in general.

\section{PI(3)K, Akt, and HIF-1 $\alpha$ are required for VEGF expression that is negatively regulated by wild-type PTEN}

Figure 3 illustrates that wild-type PTEN inhibits various hypoxia-inducible genes shown previously to be depen- dent on hypoxia-inducible factor 1 (HIF-1) (Semenza 1998). HIF-1 is a heterodimer composed of a constitutively expressed HIF-1 $\beta$ /ARNT subunit and a hypoxiastabilized HIF-1 $\alpha$ subunit (Semenza 1998). Normally, HIF- $1 \alpha$ is expressed constitutively but rapidly degraded under oxic conditions by ubiquitin-mediated degradation (Semenza 1998). To evaluate the role of PI(3)K and Akt in HIF-1 $\alpha$-dependent transactivation, we used a reporter construct containing five tandem repeats of the hypoxia-responsive element (HRE) from the erythropoietin gene, which has been shown previously to be HIF-1 responsive (Semenza et al. 1991; Mazure et al. 1997). Similar patterns of VEGF and HRE reporter activity were induced by hypoxic exposure and inhibited by wild-type PTEN expression (Fig. 4A). We also found that constitutively active $\mathrm{PI}(3) \mathrm{K}\left(\mathrm{p} 110^{\star}\right)$ and Akt (myr-Akt) were sufficient to transactivate both VEGF and HRE reporter constructs to levels comparable to IGF-1 stimulation (Fig. 4A). However, whereas the p110* reporter stimulation could be attenuated by PTEN, myr-Akt could not. It has been reported previously that myr-Akt is unrespon-

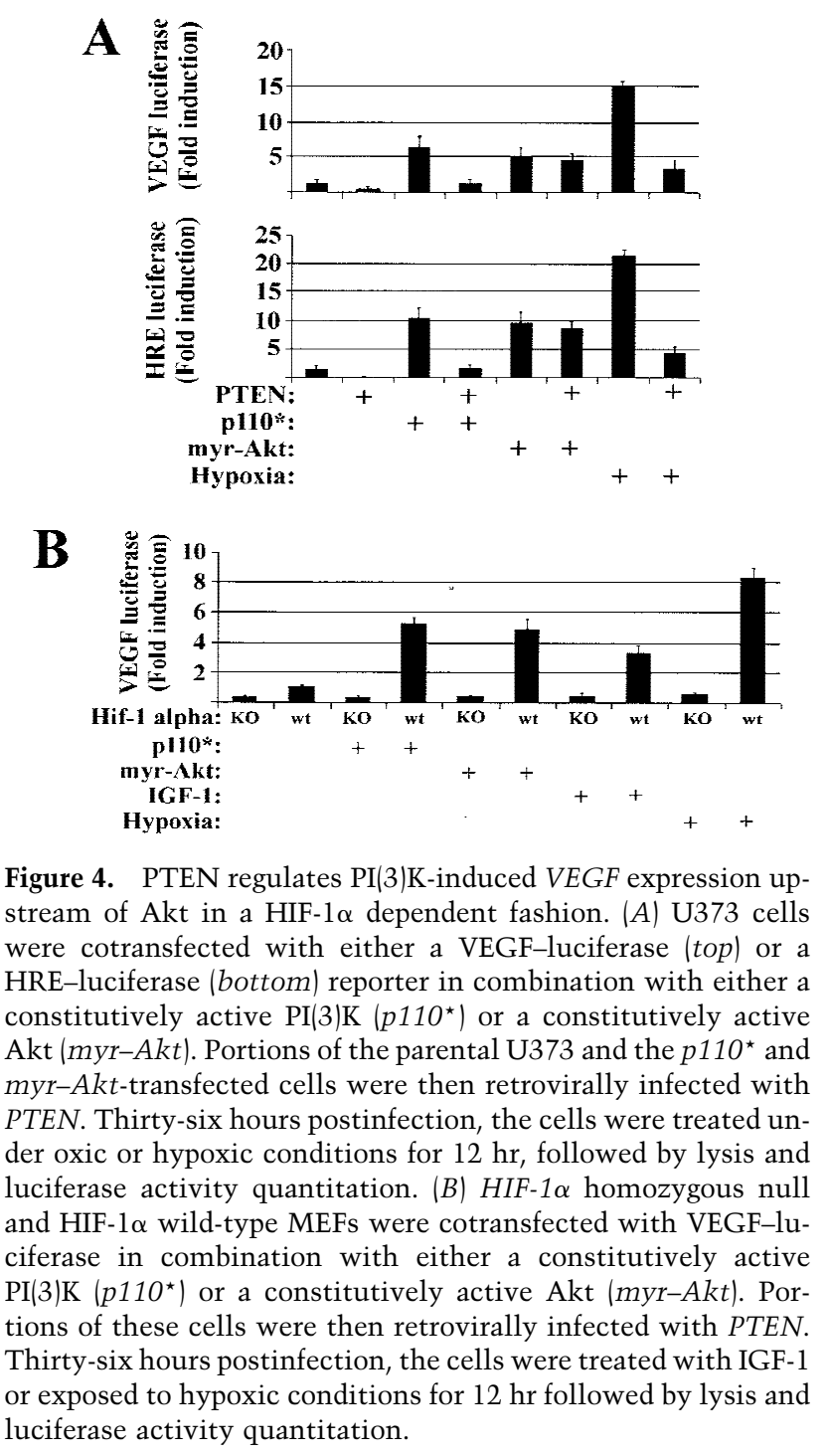


sive to PTEN expression (Li et al. 1998), supporting the concept that $\operatorname{PIP}(3,4) / \mathrm{PIP}(3,4,5)$ binding serves primarily as a localization signal (Kohn et al. 1996).

To genetically link hypoxia and IGF-1 activation of $\mathrm{PI}(3) \mathrm{K} /$ Akt to HIF-mediated transactivation, we studied the ability of the $\mathrm{PI}(3) \mathrm{K} /$ Akt pathway to modulate VEGF reporter activity in mouse embryo fibroblasts (MEFs) derived from homozygous null HIF- $1 \alpha$ mice (Ryan et al. 1998). Hypoxia, IGF-1, and constitutively active forms of $\mathrm{PI}(3) \mathrm{K}$ and Akt were all dependent on HIF-1 $\alpha$ for VEGF reporter transactivation (Fig. 4B). Thus, hypoxia and IGF-1 stimulate PI(3)K and Akt, which leads to HIF-1 $\alpha$ dependent VEGF transactivation.

\section{PTEN and Akt mediate degradation/stabilization of $H I F-1 \alpha$}

Under low oxygen conditions, HIF- $1 \alpha$ is stabilized by an undetermined mechanism that is necessary for translocation, heterodimerization, and transactivation (Semenza 1998). To determine whether PTEN expression altered the stability of HIF-1 $\alpha$ PTEN-infected cells were exposed to hypoxic challenge for various periods of time (Fig. 5A). PTEN completely suppressed the stabilization of HIF-1 $\alpha$ protein by hypoxia, indicating a possible role for PI(3)K stabilization of HIF- $1 \alpha$ (Fig. 5A). To explore the
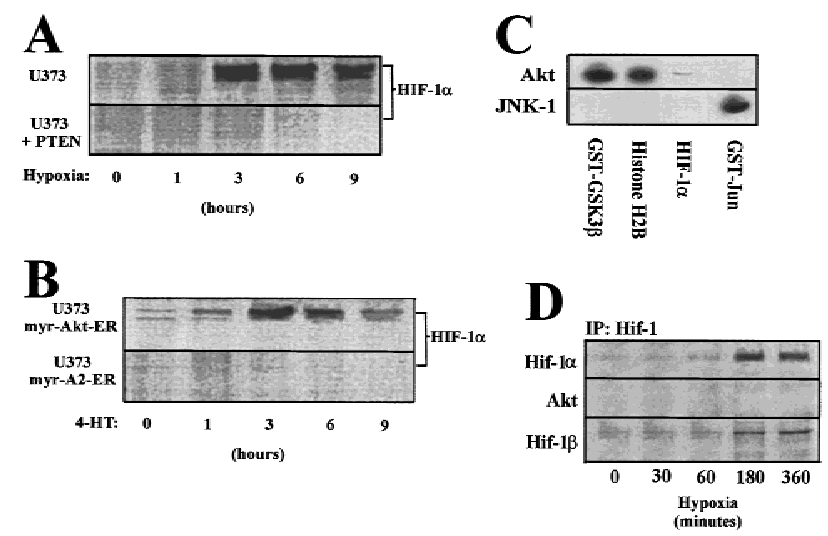

Figure 5. Akt stimulates HIF-1 $\alpha$ stabilization. (A) U373 cells were retrovirally infected with wild-type PTEN. Thirty-six hours postinfection, U373 parental cells and PTEN-expressing U373 were subjected to hypoxia for the indicated time. Cells were lysed at the indicated times followed by SDS-PAGE, transfer, and immunoblotting with anti-HIF- $1 \alpha .(B)$ Cells were retrovirally infected with myr-Akt-ER or myr-A2-ER. Thirty-six hours postinfection, the cells were subjected to induction by 4-HT for the indicated time and analyzed as in A. (C) U373 cells were serum-deprived and subjected to $1 \mathrm{hr}$ of hypoxia to activate Akt or to UV-C $\left(10 \mathrm{~J} / \mathrm{m}^{2}\right)$ for JNK-1 activation for use in immune complex kinase assays. Reactions were performed using 500 ng of either histone H2B, GST-jun, GST-GSK-3 $\beta$, or HIF- $1 \alpha$ as substrates and Akt or JNK-1 immunoprecipitations for in vitro kinase assays. Kinase reactions were subjected to SDSPAGE, and gels were dried and visualized by PhosphorImaging. $(D)$ Cells were subjected to hypoxia for the indicated times, lysed, immunoprecipitated using anti-HIF- $1 \alpha$, and subjected to SDS-PAGE, transfer, and immunoblot using anti-HIF- $1 \alpha$ antiAkt, or anti-HIF- $1 \beta$ antibodies. role of Akt in HIF-1 $\alpha$ stabilization, we infected cells with an inducible constitutively active form of Akt (myrAkt-ER) or an inactive control (myr-A2-ER) under oxic conditions (Fig. 5B). Activation of myr-Akt-ER by 4-hydroxytamoxifen $(4-\mathrm{HT})$ resulted in stabilization of HIF$1 \alpha$, whereas activated myr-A2-ER had no effect. These results strongly indicate that hypoxia mediates HIF-1 $\alpha$ stabilization through an Akt-dependent pathway in glioblastoma cells.

Akt phosphorylates proteins containing a RXRXXS/T consensus (Datta et al. 1997; Pap and Cooper 1998; Brunet et al. 1999; Kops et al. 1999|. HIF-1 $\alpha$ does not contain this motif or any significant amino acid sequence having a similar pattern. To confirm that Akt-induced HIF-1 $\alpha$ stabilization and transactivation is not a result of direct phosphorylation of HIF- $1 \alpha$, we used HIF- $1 \alpha$ as a substrate in in vitro kinase assays (Fig. 5C). HIF-1 $\alpha$ was a poor substrate for Akt compared with known Akt substrates GSK-3 $\beta$ and histone H2B. JNK-1 kinase activity is included as a negative control to confirm the specificity of Akt kinase activity. These results suggest that Akt modulates an undetermined downstream effector that regulates HIF- $1 \alpha$ stabilization.

Often signaling complexes are formed that allow for the identification of pathway components. We immunoprecipitated HIF-1 $\alpha$ from hypoxia-stimulated cells at various time points to detect any possible Akt and HIF$1 \alpha$ complex formation (Fig. 5D). No detectable Akt/HIF$1 \alpha$ interaction was detectable, whereas HIF- $1 \alpha$ and HIF$1 \beta$ complexes formed as expected. Although it is possible that Akt and HIF-1 $\alpha$ interactions are too transitory or labile to be detected, the lack of an Akt phosphorylation site, coupled with no significant in vitro phosphorylation, strongly suggests that Akt is modulating other protein(s) that increase HIF-1 $\alpha$ stabilization.

\section{Discussion}

In this study we observed that PTEN inactivation leads to hypoxia-inducible gene expression in glioblastoma lines irrespective of PTEN's effects on apoptosis and cell cycle control. We have shown that PTEN can regulate hypoxia- and growth-factor stimulated transcription of VEGF and HRE promoters. Interestingly, stimulation of Akt by growth factors, $\mathrm{p} 110^{\star}$, or expression of myr-Akt generated approximately one-fifth to one-third of the reporter response compared with hypoxia. This suggests that hypoxia potentiates the transactivation of HIF-regulated genes by other mechanisms in addition to Akt. We have shown additionally that HIF- $1 \alpha$ is not a direct substrate for Akt but that HIF-1 $\alpha$ stabilization is signaled through Akt. Cumulatively, these findings suggest a new role for PTEN mutations in the regulation of hypoxiainducible gene expression and give insight into why these mutations are observed predominantly in the late stages of tumor development.

Although multiple studies have implicated a role of PTEN in apoptosis through Akt, apoptosis and angiogenesis need not be mutually exclusive events. As tumor growth exceeds vascular density, the tumor develops 
nonvascularized areas in which metabolic byproducts, acidosis, low growth factor and nutrients, as well as hypoxia, stimulate apoptosis (Yuan and Glazer 1998). Thus, apoptosis driven by the tumor microenvironment could potentially select for loss of negative regulators of apoptosis, such as PTEN, as has been shown for other tumor suppressors that regulate apoptosis, such as $p 53$ (Graeber et al. 1996). Therefore, loss of PTEN would both increase cell survival in an adverse tumor microenvironment and increase responsiveness to hypoxia-induced HIF-1 activity that would stimulate angiogenic gene expression as well as other essential genes required to survive under low oxygen conditions. This study suggests that glioblastoma cell lines are very apoptotically resistant in a PTEN-independent fashion, further inferring alterations in apoptotic genes irrespective of PTEN loss and provides alternative explanations for the importance of PTEN mutations in tumor expansion.

PTEN is not the only tumor suppressor gene implicated in HIF- $1 \alpha$ regulation. The tumor suppressor protein Von-Hippel-Lindau (VHL) also regulates HIF-1 $\alpha$ expression by modulating its protein stability, presumably via its E3 ubiquitin ligase activity (Iwai et al. 1999; Maxwell et al. 1999). Tumor cells that have mutant forms of VHL exhibit increased expression of many HIF-regulated genes under aerobic conditions. In contrast, PTEN mutations have minimal effect on oxic expression of HIFregulated genes but potentiate their induction following hypoxia or growth factor stimulation.

The frequency of PTEN mutation underscores how the most frequently mutated genes in cancer often control multiple facets of tumorigenesis. For instance, p53 is implicated in apoptosis, cell cycle control, and genomic instability (Giaccia and Kastan 1998), whereas ras is implicated in cell cycle, apoptosis, and angiogenesis (Campbell et al. 1998). In contrast, the ultimate effectors of apoptosis, the caspases, are infrequently mutated in cancers (Mandruzzato et al. 1997). PTEN mutations result in a well-documented deregulation of critical lipid second messengers that control pivotal steps in pathways that suppress apoptosis, increase proliferation, and stimulate angiogenesis. Thus, the finding that wild-type PTEN controls multiple avenues of tumor function makes it a likely target for therapeutic intervention in tumors such as glioblastoma or prostate cancer in which gene therapy approaches are feasible.

\section{Materials and methods}

Cell culture and reagents

U373, SF188, and SF210 glioblastoma cell lines were maintained in DMEM containing $10 \%$ (vol/vol) FBS (GIBCO BRL). All experiments were performed at $80 \%-100 \%$ confluence. The HIF-1 $\alpha$ nullizygous and parental cell lines (Ryan et al. 1998) were maintained in DMEM containing $15 \%$ (vol/vol) FBS. IGF-1 (GIBCO BRL) and wortmannin (Biomol) were prepared as $1000 \times$ stock solutions. The antibodies used were Akt and Akt/Ser-473 (New England Biolabs no. 9272 and 9271, respectively), JNK-1 (Santa Cruz SC-571), PTEN (Santa Cruz SC-571, UBI-ID 07016), and HIF- $1 \alpha$ and HIF-1 $\beta$ (Transduction Labs. H72320 and A78420, respectively).

\section{Apoptosis}

Apoptosis was quantified as described previously (Graeber et al. 1996). Briefly, following treatment, cells were incubated with $2 \mu \mathrm{g} / \mathrm{ml}$ each of bis-benzamide (Hoechst no. 33342, Sigma) and propidium iodide (Sigma) for $15 \mathrm{~min}$. Viability ratios (number of apoptotic cells/total number of cells) were determined by scoring low-magnification fields of randomly selected fields for cells with condensed and fragmented nuclei and loss of membrane integrity. Fields of cells expressing GFP-PTEN under low magnification were referenced to Hoechst/propidium iodide on the same field by switching fluorescent filters.

\section{$\left[{ }^{3} \mathrm{H}\right]$ Thymidine incorporation}

Cells were seeded in $35-\mathrm{mm}$ plates and infected with adenoviral wildtype PTEN or phosphatase-deficient PTEN. Forty-eight hours after infection, the cells were serum deprived for $48 \mathrm{hr}$ in DMEM plus $300 \mu \mathrm{g} / \mathrm{ml}$ G418 (GIBCO BRL). The cells were treated as indicated and cultured in 2 $\mathrm{ml}$ of fresh medium containing $1 \mu \mathrm{Ci} / \mathrm{ml}\left[\right.$ methyl $\left.{ }^{3} \mathrm{H}\right]$ thymidine $5^{\prime}$-triphosphate (NEN Life Science Products), $300 \mu \mathrm{g} / \mathrm{ml}$ G418 for another 18 hr. Serum and hypoxia were administered simultaneously to the cultures. To eliminate the possibility that variations in cell density between plates would cause variations in ${ }^{3} \mathrm{H}$ incorporation, two additional dishes were plated and used to count cell number for each transfection at the time when $\left[{ }^{3} \mathrm{H}\right]$ thymidine was added. For harvesting cells, the growth medium containing $\left[{ }^{3} \mathrm{H}\right]$ thymidine was removed, and the cells were washed twice with PBS. The cells were rinsed twice with $2 \mathrm{ml}$ of ice-cold $5 \%$ TCA and lysed by incubation in $1.5 \mathrm{ml}$ of $0.25 \mathrm{M} \mathrm{NaOH}$ for $15 \mathrm{~min}$ at room temperature. A $0.6 \mathrm{ml}$-aliquot of each lysate was used for counting $\left[{ }^{3} \mathrm{H}\right]$ thymidine incorporation. For all experiments, triplicate plates were used and mean values were graphed.

Immunoblots and kinase assays

Akt and phospho-Akt were immunoprecipitated, resolved by $12.5 \%$ SDSPAGE, transferred to PVDF, blotted using PhosphoPlus Akt (Ser-473) Antibody Kit (New England Biolabs), visualized using a Vistra Western ECF Blotting Kit (Amersham L.S.), and quantitated by Fluorimager (Molecular Dynamics). In vitro kinase reactions were performed for $40 \mathrm{~min}$ at $30^{\circ} \mathrm{C}$ with constant shaking in $30-\mu l$ reaction volumes containing $500 \mathrm{ng}$ of histone H2B, GST-jun, GST-GSK-3 $\beta$, or immunoprecipitated HIF- $1 \alpha$ as substrates, $10 \mu \mathrm{Ci}$ of $\left[{ }^{32} \mathrm{P}\right] \mathrm{ATP}$, and immunoprecipitations of active Akt or JNK-1 as described (Datta et al. 1997). Kinase reactions were stopped by the addition of SDS-PAGE loading buffer and boiling for 5 min. The kinase reaction products were resolved by $12.5 \%$ SDS-PAGE, and the gels were washed for $5 \mathrm{~min}$ in $\mathrm{dH}_{2} \mathrm{O}$, dried, and visualized by PhosphorImaging (Molecular Dynamics).

Constructs, expression, and reporter assays

Construction and preparation of the VEGF and HRE luciferase reporter constructs, $110^{*}$, PLXN-PTEN, myr-Akt, myr-Akt-ER, and myr-A2$E R$ were described previously (Hu et al. 1995; Mazure et al. 1997; HaasKogan et al. 1998; Kohn et al. 1998). Retroviral infection was performed by three sequential 6-hr incubations containing $5 \mu \mathrm{g} / \mathrm{ml}$ Polybrene, followed by recovery for 2-6 days. Adenoviruses expressing the PTEN or PTENA genes and capable of replicating in the "packaging" 293 cell line were made using the pAdEasy protocol. The virus was stored in singleuse aliquots at $-80^{\circ} \mathrm{C}$. U373 cells were routinely infected at an MOI of 10 and cells were harvested $48 \mathrm{hr}$ post infection. Transfections were performed using Lipofectamine Plus (GIBCO BRL). Luciferase assays were performed using the TB161 Luciferase Reporter Kit (Promega) and quantitated using a Monolight 2010 luminometer (Analytical Luminescence Laboratory).

\section{RNA isolation and Northern blotting}

Total RNA was isolated with TRIzol (GIBCO BRL). Total RNA/lane (10 $\mu \mathrm{g})$ was denatured with glyoxal and size fractionated by electrophoresis on $1.4 \%$ agarose/sodium phosphate gels. RNA was transferred to nylon membranes and UV cross-linked. PGK, PFK, and COX-1 were purchased as GEM clones (Genome Systems). Probes were cut out of the inserts with EcoRI and NotI from pINCY. The VEGF probe comprises a 600-bp fragment of the 5'UTR of VEGF. Radiolabeled probes were generated by random priming (Rediprime, Amersham) of cDNAs representing the complete coding sequences of $P G K, P F K, \mathrm{c}-f o s$, and $C O X-1$. Blots were prehybridized and hybridized in ExpressHyb solution (Clontech) at $65^{\circ} \mathrm{C}$, washed several times in $2 \times$ SSC/0.05\% SDS and $0.2 \times$ SSC/0.1\% SDS at $65^{\circ} \mathrm{C}$, exposed to a PhosphorImager plate overnight, and visualized on a Storm 860 PhosphorImager (Molecular Dynamics). 


\section{Acknowledgments}

This paper is dedicated to the memory of Leila Diamond-mentor, scientist, and friend. We commend the steller administrative contributions of S. Clarke and S. Goodrich. W.Z. is supported by a Markey Trust Fellowship in Molecular Medicine and an NIH predoctoral fellowship (CA 09302). A.J.G. is supported by NIH grants (CA-73832 and CA-67166). D.H.-K. is supported by NIH grant (MO1RRO1271) and an RSNA Scholar Award.

The publication costs of this article were defrayed in part by payment of page charges. This article must therefore be hereby marked "advertisement" in accordance with 18 USC section 1734 solely to indicate this fact.

\section{References}

Aoki, M., O. Batista, A. Bellacosa, P. Tsichlis, and P.K. Vogt. 1998. The akt kinase: Molecular determinants of oncogenicity. Proc. Nat1. Acad. Sci. 95: 14950-14955.

Brunet, A., A. Bonni, M.J. Zigmond, M.Z. Lin, P. Juo, L.S. Hu, M.J. Anderson, K.C. Arden, J.Blenis, and M.E. Greenberg. 1999. Akt promotes cell survival by phosphorylating and inhibiting a Forkhead transcription factor. Cell 96: 857-868.

Campbell, S.L., R. Khosravi-Far, K.L. Rossman, G.J. Clark, and C.J. Der. 1998. Increasing complexity of Ras signaling. Oncogene 17: 13951413.

Cantley, L.C. and B.G. Neel. 1999. New insights into tumor suppression: PTEN suppresses tumor formation by restraining the phosphoinositide 3-kinase/AKT pathway. Proc. Natl. Acad. Sci. 96: 4240-4245.

Datta, S.R., H. Dudek, X. Tao, S. Masters, H. Fu, Y. Gotoh, and M.E. Greenberg. 1997. Akt phosphorylation of BAD couples survival signals to the cell-intrinsic death machinery. Cell 91: 231-241.

Davies, M.A., D. Koul, H. Dhesi, R. Berman, T.J. McDonnell, D. McConkey, W.K. Yung, and P.A. Steck. 1998. Adenoviral transgene expression of MMAC/PTEN in human glioma cells inhibits Akt activation and induces anoikis. Cancer Res. 58: 5285-5290.

Di Cristofano, A., B. Pesce, C. Cordon-Cardo, and P.P. Pandolfi. 1998. Pten is essential for embryonic development and tumour suppression. Nat. Genet. 19: 348-355.

Diehl, J.A., M. Cheng, M.F. Roussel, and C.J. Sherr. 1998. Glycogen synthase kinase-3beta regulates cyclin D1 proteolysis and subcellular localization. Genes \& Dev. 12: 3499-3511.

Fruman, D.A., R.E. Meyers, and L.C. Cantley. 1998. Phosphoinositide kinases. Annu. Rev. Biochem. 67: 481-507.

Giaccia, A.J. and M.B. Kastan. 1998. The complexity of p53 modulation: Emerging patterns from divergent signals. Genes \& Dev. 12: 29732983.

Graeber, T.G., C. Osmanian, T. Jacks, D.E. Housman, C.J. Koch, S.W. Lowe, and A.J. Giaccia. 1996. Hypoxia-mediated selection of cells with diminished apoptotic potential in solid tumours. Nature 379: 88-91.

Haas-Kogan, D., N. Shalev, M. Wong, G. Mills, G. Yount, and D. Stokoe. 1998. Protein kinase B (PKB/Akt) activity is elevated in glioblastoma cells due to mutation of the tumor suppressor PTEN/MMAC. Curr. Biol. 8: 1195-1198.

Hu, Q., A. Klippel, A.J. Muslin, W.J. Fantl, and L.T. Williams. 1995. Ras-dependent induction of cellular responses by constitutively active phosphatidylinositol-3 kinase. Science 268: 100-102.

Iwai, K., K. Yamanaka, T. Kamura, N. Minato, R.C. Conaway, J.W. Conaway, R.D. Klausner, and A. Pause. 1999. Identification of the von Hippel-Lindau tumor-suppressor protein as part of an active E3 ubiquitin ligase complex. Proc. Nat1. Acad. Sci. 96: 12436-12441.

Khwaja, A., P. Rodriguez-Viciana, S. Wennstrom, P.H. Warne, and J. Downward. 1997. Matrix adhesion and Ras transformation both activate a phosphoinositide 3-OH kinase and protein kinase B/Akt cellular survival pathway. EMBO J. 16: 2783-2793.

Kohn, A.D., F. Takeuchi, and R.A. Roth. 1996. Akt, a pleckstrin homology domain containing kinase, is activated primarily by phosphorylation. J. Biol. Chem. 271: 21920-21926.

Kohn, A.D., A. Barthel, K.S. Kovacina, A. Boge, B. Wallach, S.A. Summers, M.J. Birnbaum, P.H. Scott, J.C. Lawrence Jr, and R.A. Roth. 1998. Construction and characterization of a conditionally active version of the serine/threonine kinase Akt. J. Biol. Chem. 273: 1193711943 .
Kops, G.J.P.L., N.D. de Ruiter, A.M. De Viries-Smits, D.R. Powell, J.L. Bos, and B.M. Burgering. 1999. Direct control of the Forkhead transcription factor AFX by protein kinase B. Nature 398: 630-634.

Li, J., C. Yen, D. Liaw, K. Podsypanina, S. Bose, S.I. Wang, J. Puc, C. Miliaresis, L. Rodgers, R. McCombie et al. 1997. PTEN, a putative protein tyrosine phosphatase gene mutated in human brain, breast, and prostate cancer. Science 275: 1943-1947.

Li, J., L. Simpson, M. Takahashi, C. Miliaresis, M.P. Myers, N. Tonks, and R. Parson. 1998. The PTEN/MMAC1 tumor suppressor induces cell death that is rescued by the AKT/protein kinase B oncogene. Cancer Res. 58: 5667-5672.

Liaw, D., D.J. Marsh, J. Li, P.L. Dahia, S.I. Wang, Z. Zheng, S. Bose, K.M Call, H.C. Tsou, M. Peacocke et al. 1997. Germline mutations of the PTEN gene in Cowden disease, an inherited breast and thyroid cancer syndrome. Nat. Genet. 16: 64-67.

Maehama, T. and J.E. Dixon. 1998. The tumor suppressor, PTEN/ MMAC1, dephosphorylates the lipid second messenger, phosphatidylinositol 3,4,5-trisphosphate. J. Biol. Chem. 273: 13375-13378.

Mandruzzato, S., F. Brasseur, G. Andry, T. Boon, and P. van der Bruggen. 1997. A CASP-8 mutation recognized by cytolytic T lymphocytes on a human head and neck carcinoma. J. Exp. Med. 186: 785-793.

Marsh, D.J., P.L. Dahia, Z. Zheng, D. Liaw, R. Parsons, R.J. Gorlin, and C. Eng. 1997. Germline mutations in PTEN are present in BannayanZonana syndrome. Nat. Genet. 16: 333-334.

Maxwell, P.H., M.S. Wiesener, G.W. Chang, S.C. Clifford, E.C. Vaux, M.E. Cockman, C.C. Wykoff, C.W. Pugh, E.R. Maher, and P.J. Ratcliffe. 1999. The tumour suppressor protein VHL targets hypoxia-inducible factors for oxygen-dependent proteolysis. Nature 399: 271275.

Mazure, N.M., E.Y. Chen, K.R. Laderoute, and A.J. Giaccia. 1997. Induction of vascular endothelial growth factor by hypoxia is modulated by a phosphatidylinositol 3-kinase/Akt signaling pathway in Ha-rastransformed cells through a hypoxia inducible factor-1 transcriptional element. Blood 90: 3322-3331.

Pap, M. and G.M. Cooper. 1998. Role of glycogen synthase kinase-3 in the phosphatidylinositol 3-Kinase/Akt cell survival pathway. J. Biol. Chem. 273: 19929-19932.

Petersdorf, S.H. and R.B. Livingston. 1994. High dose chemotherapy for the treatment of malignant brain tumors. J. Neurooncol. 20: 155-163.

Ryan, H.E., J. Lo, and R.S. Johnson. 1998. HIF-1 alpha is required for solid tumor formation and embryonic vascularization. EMBO J. 17: 30053015.

Semenza, G.L. 1998. Hypoxia-inducible factor 1: Master regulator of O2 homeostasis. Curr. Opin. Genet. Dev. 8: 588-594.

Semenza, G.L., M.K. Nejfelt, S.M. Chi, and S.E. Antonarakis. 1991. Hypoxia-inducible nuclear factors bind to an enhancer element located 3' to the human erythropoietin gene. Proc. Natl. Acad. Sci. 88: 56805684.

Stambolic, V., A. Suzuki, J.L. de la Pompa, G.M. Brothers, C. Mirtsos, T. Sasaki, J. Ruland, J.M. Penninger, D.P. Siderovski, and T.W. Mak. 1998. Negative regulation of PKB/Akt-dependent cell survival by the tumor suppressor PTEN. Cell 95: 29-39.

Steck, P.A., M.A. Pershouse, S.A. Jasser, W.K. Yung, H. Lin, A.H. Ligon, L.A. Langford, M.L. Baumgard, T. Hattier, T. Davis et al. 1997. Identification of a candidate tumour suppressor gene, MMAC1, at chromosome 10q23.3 that is mutated in multiple advanced cancers. Nat. Genet. 15: 356-362.

Wang, D., H.J. Huang, A. Kazlauskas, and W.K. Cavenee. 1999. Induction of vascular endothelial growth factor expression in endothelial cells by platelet-derived growth factor through the activation of phosphatidylinositol 3-kinase. Cancer Res. 59: 1464-1472.

Warren, R.S., H. Yuan, M.R. Matli, N. Ferrara, and D.B. Donner. 1996 Induction of vascular endothelial growth factor by insulin-like growth factor 1 in colorectal carcinoma. J. Biol. Chem. 271: 2948329488.

Wesseling, P., D.J. Ruiter, and P.C. Burger. 1997. Angiogenesis in brain tumors; pathobiological and clinical aspects. J. Neurooncol. 32: 253265.

Yuan, J. and P.M. Glazer. 1998. Mutagenesis induced by the tumor microenvironment. Mutat. Res. 400: 439-446.

Zelzer, E., Y. Levy, C. Kahana, B.Z. Shilo, M. Rubinstein, and B. Cohen. 1998. Insulin induces transcription of target genes through the hypoxia-inducible factor HIF-1alpha/ARNT. EMBO J. 17: 5085-5094. 


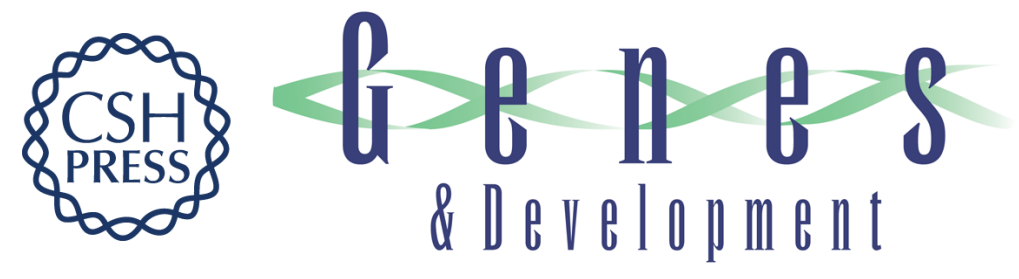

\section{Loss of PTEN facilitates HIF-1-mediated gene expression}

Wayne Zundel, Cornelia Schindler, Daphne Haas-Kogan, et al.

Genes Dev. 2000, 14:

Access the most recent version at doi:10.1101/gad.14.4.391

References This article cites 38 articles, 21 of which can be accessed free at: http://genesdev.cshlp.org/content/14/4/391.full.html\#ref-list-1

License

Email Alerting Receive free email alerts when new articles cite this article - sign up in the box at the top Service right corner of the article or click here.

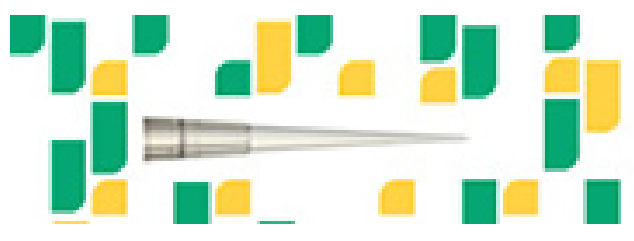

Focused on your science. 